\title{
Impact of an SRA (hexylene glycol) on irreversible drying shrinkage and pore solution properties of cement pastes
}

Hafsa Rahoui ${ }^{\mathrm{a}, \mathrm{c}}$, Ippei Maruyama ${ }^{\mathrm{b}}$, Matthieu Vandamme ${ }^{\mathrm{a}}$, Jean-Michel Pereira $^{\mathrm{a}}$, Martin Mosquet $^{\mathrm{c}}$

${ }^{a}$ Navier, Ecole des Ponts, Univ Gustave Eiffel, CNRS, Marne-la-Vallée, France ${ }^{b}$ Graduate School of Environmental Studies, Nagoya University - Nagoya, Japan ${ }^{c}$ LafargeHolcim Innovation Center - Saint-Quentin Fallavier, 38291, France 


\title{
Impact of an SRA (hexylene glycol) on irreversible drying shrinkage and pore solution properties of cement pastes
}

\begin{abstract}
Cementitious materials shrink when exposed to decreasing relative humidities, which may result in cracking. Shrinkage reducing admixtures (SRAs) can be used to reduce this drying shrinkage. Although many studies have shown that SRAs reduce the surface tension of the pore solution, the effects of SRAs on other pore solution properties and their relationship to drying shrinkage have been poorly characterized. In this work, we investigate the impact of an SRA (hexylene glycol) on the drying and re-humidification of a cement paste over an extended relative humidity range. The reduction in the first drying shrinkage by the SRA depends on relative humidity. The SRA also significantly reduces the irreversible drying shrinkage. We concluded that the SRA impacts drying shrinkage by acting on the capillary forces, by acting on the specific range of relative humidity over which those forces occur, and potentially by acting on the surface stresses through pore wall adsorption.
\end{abstract}

Keywords: First drying shrinkage, mass change isotherms, SRA

\section{Introduction}

Shrinkage reducing admixtures (SRAs) are organic compounds that reduce both the autogenous shrinkage [1, 2, 3, 4, 5, 6, 7, and the drying shrinkage in cement-based materials [3, 7, 8, 9, 10, 11, 12, 13. The effects of SRAs on 5 both autogenous and drying shrinkage can help to reduce the risk of cracking in cement-based materials [7, 9, 14]. Drying shrinkage of cementitious materials depends on additives and the drying history, which impacts the drying shrinkage 
of cement-based materials, since the first drying shrinkage is irreversible, in contrast to subsequent drying cycles. This feature was first highlighted by Helmuth and Turk [15], who found that both cement pastes and alite pastes exhibit irreversible first drying shrinkage (the samples do not regain their initial length after re-humidification), followed by reversible drying shrinkage.

Suppliers often attribute the ability of the SRAs to reduce the drying shrinkage to their ability reducing the surface tension of the pore solution, and the resulting capillary forces. However, the reduction in drying shrinkage is not correlated to the ability of SRAs to reduce the surface tension [16. Furthermore, whether SRAs are more efficient at some relative humidities than at other ones is unclear. In this work, we investigate the impact of an SRA on the pore solution, examining more than just the ability of the SRA to reduce surface tension.

20 We also explore how the influence of the SRA on the pore solution is linked to its ability to reduce drying shrinkage and how SRA affects the irreversibility of the drying shrinkage isotherms. Using our results, we analyze the mechanisms through which SRAs act on drying shrinkage.

\section{Materials and methods}

25 2.1. Materials

Three types of samples with different SRA contents were manufactured. All three samples had two properties in common: 1) the solution to cement ratio was 0.55 (by mass), where the solution mass refers to the combined mass of SRA and water; and 2) the SRA added to the mixtures was hexylene glycol, also known as 2-methyl-2,4-pentanediol (Sigma Aldrich). The SRA contents tested in this study were $0 \%, 4 \%$, and $8 \%$ of the mass of cement. The cement pastes were labeled PP-L, SR4-L and SR8-L, respectively, where, 'PP' represents the plain paste (no SRA added); 'SR[X]' represents pastes containing an SRA mass content of $[\mathrm{X}]$ (in percent) with respect to cement content; and ' $\mathrm{L}$ ' represents

35 low alkali content in the cement pastes. The composition of the cement is provided in Table 1. XRF measurements were conducted with X Magix PRO 


\begin{tabular}{|c|c|c|c|}
\hline \multicolumn{2}{|c|}{ Composition from XRF } & \multicolumn{2}{c|}{ Composition from XRD } \\
\hline \hline Component & Mass fraction, \% & Phase & Mass fraction, \% \\
\hline $\mathrm{SiO}_{2}$ & 22.5 & Alite $\mathrm{C}_{3} \mathrm{~S}$ & $69.2 \pm 0.5$ \\
$\mathrm{Al}_{2} \mathrm{O}_{3}$ & 2.9 & Belite $\mathrm{C}_{2} \mathrm{~S}$ & $19.1 \pm 1.6$ \\
$\mathrm{Fe}_{2} \mathrm{O}_{3}$ & 2.25 & Ferrite $\mathrm{C}_{4} \mathrm{AF}$ & $6.8 \pm 0.5$ \\
$\mathrm{CaO}$ & 66.97 & Aluminate $\mathrm{C}_{3} \mathrm{~A}$ & $1 \pm 0.2$ \\
$\mathrm{MgO}$ & 0.85 & Calcite $\mathrm{C} \overline{\mathrm{C}}$ & $2.4 \pm 0.5$ \\
$\mathrm{SO}_{3}$ & 2.22 & Periclase $\mathrm{MgO}$ & $0.6 \pm 0.2$ \\
$\mathrm{~K}_{2} \mathrm{O}$ & 0.17 & Gypsum $\mathrm{C} \overline{\mathrm{S}} \mathrm{H}_{2}$ & $0.6 \pm 0.7$ \\
$\mathrm{Na}_{2} \mathrm{O}$ & 0.12 & Hemihydrate $\mathrm{C} \overline{\mathrm{S}} \mathrm{H}_{0.5}$ & $0.4 \pm 0.2$ \\
$\left(\mathrm{Na}_{2} \mathrm{O}\right)_{e q}$ & 0.23 & \multicolumn{2}{|c}{} \\
\hline
\end{tabular}

Table 1: Chemical composition of the ordinary Portland cement, in mass fractions, according to X-ray fluorescence (XRF) and X-ray diffraction (XRD) measurements. The \pm values represent the standard deviations. $\left(\mathrm{Na}_{2} \mathrm{O}\right)_{e q}$ corresponds to $\mathrm{Na}_{2} \mathrm{O}+\mathbf{0 . 6 5 8} \mathrm{K}_{2} \mathrm{O}$.

on unhydrated cement. XRD measurements were conducted according to the procedure described in [17.

The samples were prepared according to a three-step protocol that did not correspond to any official standards:

1. Mixing: deionized water, stored overnight at room temperature $\left(20^{\circ} \mathrm{C}\right)$, was pre-mixed with the appropriate amount of SRA. To keep solution masses constant, water was replaced by an equivalent amount of SRA in the solutions. The solution of water and SRA was then mixed with the cement initially at a solution to cement ratio of 0.3 for 2 minutes. The remaining solution was then added to the premixed paste and mixed again for 2 minutes. All mixing was conducted using a Renfert twister mixer at $250 \mathrm{rpm}$. Next, the paste was remixed manually every 30 minutes using a plastic spatula, until the mixture formed a creamy consistency: this process took between 4 and 10 hours for the cement pastes considered 
in this study. This mixing procedure prevented bleeding for these w/c ratios. The paste was then cast into the molds, which were subjected to external vibration to minimize trapped air bubbles after the casting. The molds were wrapped in a damp cloth and a plastic sheet to prevent the samples from drying before being removed from the molds. The resulting specimens had dimensions of $3 \mathrm{~mm} \times 13 \mathrm{~mm} \times 300 \mathrm{~mm}$. The molds were not greased prior to casting to prevent potential effects on the drying shrinkage from the grease.

2. Cutting: the pastes were demolded after 5 days. Demolding was difficult at an earlier age because the samples were very thin (i.e., $3 \mathrm{~mm}$ ) and long (i.e., $300 \mathrm{~mm}$ ), making the samples prone to breakage. Every sample was cut twice with a diamond saw at a rotational speed of $70 \mathrm{rpm}$, resulting in specimens with dimensions of $3 \mathrm{~mm} \times 13 \mathrm{~mm} \times 100 \mathrm{~mm}$. Deionized water was used during the cutting process to lubricate the surfaces, facilitating the cutting process, and preventing overheating by cooling the surfaces.

3. Curing: samples were cured at $20^{\circ} \mathrm{C}$ for 90 days in sealed aluminum bags. The 90-day curing period resulted in mature pastes with a high degree of hydration. Unlike curing under lime saturate solution, this sealed curing condition, which was developed in-house and corresponds to no standard, prevents the leaching of SRA.

\subsection{Methods}

In this section, we introduce the methods used for measuring the drying shrinkage isotherms of cement pastes exposed to long-term or short-term drying, characterizing the properties of the pore solutions, and the leaching ability of the SRA from the cement pastes.

\subsubsection{Drying shrinkage measurements}

Long-term drying measurements. From the drying shrinkage experiments, we selected the dimensions of the samples, particularly the $3 \mathrm{~mm}$ thickness, to reduce the time needed to reach equilibrium and to reduce the potential 


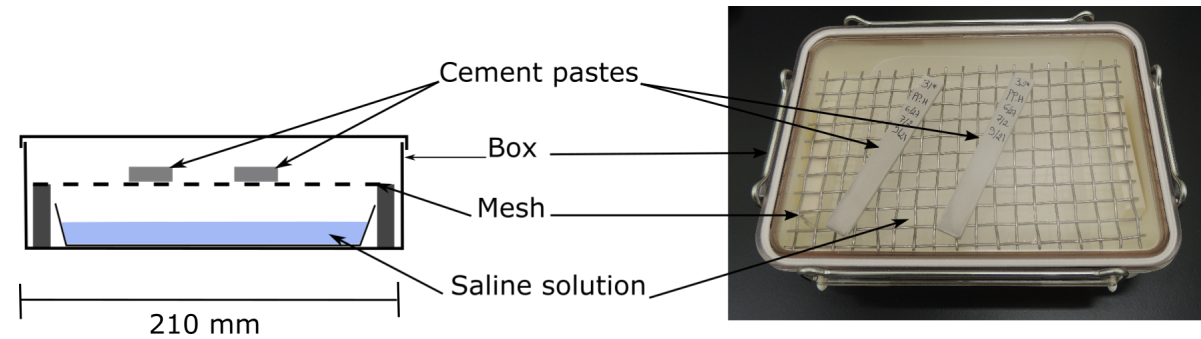

Figure 1: (left) Schematic of the box used for long-term drying and (right) photograph of box 'A', which featured this setup for sample monitoring.

80 however, Bisschop and Wittel [18 found that cement pastes with a thickness of 2 to $4 \mathrm{~mm}$ do not crack when dried.

Drying of the samples started after the 3 month sealed curing period. The samples were placed in boxes with dimensions of $210 \times 150 \times 45 \mathrm{~mm}^{3}$. Each Figure 1. Saturated salt solutions were used to control the relative humidity.

The salts and the target relative humidities are detailed in Table 2. The samples were placed on the mesh to prevent direct contact with the saturated salt solution. Eighteen boxes were used to equilibrate the cement pastes at eight different relative humidities. All boxes were equipped with relative humidity sensors. This instrumentation allowed us to monitor and confirm the relative humidity inside the box during the drying. The number of boxes that could be monitored was limited by the number of available sensors. For every relative humidity and sample type, we considered two boxes:

95

1. Box 'A', which contained at least two samples of each type. The drying shrinkage and mass loss of these samples were measured periodically to determine the point of equilibrium.

2. Box 'B', which contained at least five samples of each type. The drying shrinkage and mass of these samples were measured only twice: before drying (before being placed in the boxes with controlled relative humidity) 


\begin{tabular}{|c|c|c|}
\hline Salt & Target relative humidity (\%) & Measured relative humidity (\%) \\
\hline $\mathrm{LiCl}$ & $11^{*}$ & $12.3 \pm 0.02$ \\
\hline $\mathrm{MgCl}_{2}$ & 33 & $31.9 \pm 0.01$ \\
\hline $\mathrm{NaI}$ & $40^{*}$ & $39.5 \pm 0.01$ \\
\hline $\mathrm{Mg}\left(\mathrm{NO}_{3}\right)_{2}$ & $54^{*}$ & $54.9 \pm 0.02$ \\
\hline $\mathrm{NaBr}$ & $60^{*}$ & $60 \pm 0.01$ \\
\hline $\mathrm{NaCl}$ & $75^{*}$ & $76.3 \pm 0.03$ \\
\hline $\mathrm{KCl}$ & 85 & $84.8 \pm 0.01$ \\
\hline $\mathrm{KNO}_{3}$ & $95^{*}$ & $91.8 \pm 0.17$ \\
\hline
\end{tabular}

Table 2: Salts used in saturated solutions, the target relative humidity, and the measured relative humidity in the eight boxes used for first drying of the samples. All relative humidities marked with a star $\left(^{*}\right)$ were also considered for the re-humidification process following the first drying.

and after drying (after the samples in box ' $\mathrm{A}$ ' reached equilibrium).

This method prevented the carbonation of the samples equilibrated in box ' $\mathrm{B}$ ', since box 'B' was only opened once, after equilibrium. Because the air inside box ' $\mathrm{B}$ ' was not renewed, no $\mathrm{CO}_{2}$ was accumulated. The samples in box 'A', 
The final mass and length changes were measured for the samples in the ' $\mathrm{B}$ ' boxes, which contained at least five samples of each type, when the rate of mass variation of the ' $\mathrm{A}$ ' box samples was less than $0.01 \%$ per day. The uniaxial strain $\varepsilon$ was calculated according to the following formula:

$$
\varepsilon=\frac{l-l_{\text {ref }}}{l_{\text {ref }}}
$$

where $l$ is the measured length of the cement specimens and $l_{\text {ref }}$ represents the reference length, or the initial length of the samples immediately after sealed curing.

The relative mass change $w_{l}$ was calculated according to the following equation:

$$
w_{l}=\frac{m-m_{\text {ref }}}{m_{\text {ref }}}
$$

where $m$ is the measured mass of the cement specimen, and $m_{\text {ref }}$ is the reference mass, or the initial mass of the samples immediately after sealed curing.

Short-term drying measurements. A separate set of cement pastes were used to study the effects of short-term drying. The samples studied under short-term drying are recapitulated in Table 3 For this subset, samples with dimensions of $3 \mathrm{~mm} \times 3 \mathrm{~mm} \times 0.5 \mathrm{~mm}$ were cut using a diamond saw. Before the samples were submitted to short-term drying, they were prepared in two hydric states:

1. Some of the samples were kept in sealed curing conditions for at least 3 months: these samples are referred to as 'non-pre-dried'.

2. Other samples were dried at a relative humidity of $11 \%$ for at least 6 months after the 3 months sealed curing process: these samples are referred to as 'pre-dried'.

By comparing the humidity-induced length changes of the samples in these two hydric states we could assess how much of the drying shrinkage is irreversible. 
The length changes induced by short-term drying were measured using a imately 5 days. For the short-term drying measurements, length changes and mass changes were computed relative to the end of the plateau at $95 \%$ relative humidity at the beginning of the cycle.

Post-hydration addition of SRA. To study the impact of adding an SRA were prepared from a plain paste. SRA was added to the paste after it had cured under sealed conditions for more than 6 months. A cured plain paste was cut into $3 \mathrm{~mm} \times 3 \mathrm{~mm} \times 0.5 \mathrm{~mm}$ samples using a diamond saw. 


\begin{tabular}{|c|c|c|}
\hline Sample & Condition before measurement & Measurements \\
\hline PP-L & sealed & short-term drying, long-term drying \\
\hline SR4-L & sealed & long-term drying \\
\hline SR8-L & sealed & short-term drying, long-term drying \\
\hline PP-L-SRA & sealed & short-term drying \\
\hline PP-L-11 & prolonged drying at RH $11 \%$ & short-term drying \\
\hline SR8-L-11 & prolonged drying at RH $11 \%$ & short-term drying \\
\hline
\end{tabular}

Table 3: Types of samples used for long-term and short-term drying measurements. 'RH' stands for 'relative humidity'.

The specimen was immersed in an $18 \%$ by mass SRA solution for at least 3 days. The paste to solution (water+SRA) mass ratio was also $18 \%$. Then, the drying shrinkage and mass change were measured through short-term drying measurements. By adding SRA post-hydration, we could bypass the effects induced by the SRA on the pore structure during mixing [4, 7, 9, 12, 19.

To estimate the SRA content, the organic carbon content in the cement pastes was measured. The abundance of carbon, hydrogen, and oxygen in the cement pastes was measured using an elemental analyzer (Elementar vario MICRO cube, Elementar Inc.). Sulfanilamide $\left(\mathrm{NH}_{2} \mathrm{C}_{6} \mathrm{H}_{4} \mathrm{SO}_{2} \mathrm{NH}_{2}\right)$ was used as a standard for the carbon and hydrogen content measurements, and the results were reported in mass percentage.

\subsubsection{Characterization of pore solution of cement pastes}

For pore solution extraction, cylindrical cement pastes with a diameter of $6 \mathrm{~cm}$ and height of $7 \mathrm{~cm}$ were prepared using a high-shear mixer at LafargeHolcim Innovation Center in Lyon. The cement pastes were cured under sealed conditions for at least 9 months to ensure that the pastes reached an advanced degree of hydration before pore solution extraction.

The pore solution of our mature pastes was extracted with a hydraulic press 20]. The surface tension of the collected pore solution was analyzed using a $3 \mathrm{~S}$ tensiometer (GBX) which uses the Wilhelmy plate method for measurements. 
Some of the pore solution samples were acidified with hydrochloric acid immediately after extraction and stored in a refrigerator until their ionic composition was analyzed using coupled plasma atomic emission spectroscopy (ICP-AES) with an ICP Varian 720-ES.

\subsubsection{Characterization of leaching of SRA from cement pastes}

To evaluate whether the SRA was adsorbed to the cement hydrates, we conducted leaching experiments on cement pastes containing SRA in a synthetic pore solution. The cement paste samples were placed in contact with a liquid, and the leached species were evaluated. A synthetic pore solution (SPS) was used for leaching experiments to mimic the in-situ environment of the pore solution for a cement paste without SRA. The synthetic pore solution prevented the dissolution of hydrates in the cement paste. If the cement paste were immersed in deionized water, dissolution could occur, impacting the potential adsorption of the SRA on the cement hydrates.

The synthetic pore solution was prepared using the following protocol:

1. A plain paste was prepared and cured under sealed conditions for 7 days.

2. After demolding, the plain paste was crushed and sieved. Particles ranging between $250 \mu \mathrm{m}$ and $1.1 \mathrm{~mm}$ in size were selected and air blown for a few seconds to remove fine particles.

3. The crushed plain paste was immersed in deionized water for 7 days at a solid-to-liquid ratio of $140 \mathrm{~g} / \mathrm{L}$.

4. After solution sedimentation, the solid fraction and solution can be separated. This solution is the synthetic pore solution.

The SRA leaching experiments were conducted by successively immersing the paste containing SRA into the synthetic pore solution. The first cycle consisted of the following steps:

1. The pastes containing SRA were crushed and sieved for particles between $250 \mu \mathrm{m}$ and $1.1 \mathrm{~mm}$. 
2. The particles were immersed in the synthetic pore solution at a solidto-liquid ratio of $5 \mathrm{~g}$ of paste per $0.2 \mathrm{~L}$ of synthetic pore solution for 7 days.

At the end of each cycle, the solution was removed and analyzed for organic carbon amount. The TOC (total organic carbon) measurements were conducted using a TOC V CSH SHIMADZU. The cement paste was then immersed again in $0.2 \mathrm{~L}$ of synthetic pore solution, beginning a new cycle. A total of four cycles was conducted per type of cement paste. Both pastes containing SRA (4\% and $8 \%$ SRA content) were studied. A reproduciblity was confirmed by three sets of measurement on SR8-L sample.

The measured concentrations $C_{\text {meas,raw }}$ were corrected for the concentration $C_{S P S}$ of organic carbon present in the synthetic pore solution using the following equation:

$$
C_{\text {meas }}=C_{\text {meas }, \text { raw }}-C_{S P S}
$$

Based on the mix design, the mass $m_{C}$ of organic carbon from the SRA in the cement paste can be evaluated using the following:

$$
m_{C}=\frac{C_{S R A}}{\left(1+C_{S R A}+w / c\right)} \times m_{h c p} \times m_{\text {carbon }}
$$

where $m_{\text {carbon }}$ is the mass ratio of carbon in the SRA (for the SRA used in this work, $m_{\text {carbon }}=6 \times M_{C} / M_{\mathrm{C}_{6} \mathrm{H}_{14} \mathrm{O}_{2}}$ with $M_{C}$ representing the molar mass of carbon and $M_{\mathrm{C}_{6} \mathrm{H}_{14} \mathrm{O}_{2}}$ the molar mass of the SRA), $C_{S R A}$ is the SRA content in mass fraction relative to the cement, $w / c$ is the water-to-cement ratio, and $m_{h c p}$ is the mass of hardened cement paste in the leaching measurements.

Assuming all SRA leached from the paste (SRA is mobile or no SRA adsorbed to the cement hydrates), the theoretical concentration $C_{t h, n}$ of SRA after the $n$-th cycle of leaching could be calculated with the following:

$$
C_{t h, 1}=\frac{m_{C}}{V}
$$




$$
C_{t h, n}=C_{t h, n-1}-\frac{C_{m e a s, n-1}\left(V-V_{l e f t}\right)}{V} \text { for } n \geq 2
$$
cement paste containing $4 \%$ of SRA, while, for $\mathrm{RH}<60 \%$, the mass loss was

\footnotetext{
${ }^{1}$ Here hysteresis means that a parameter follows a different path upon drying and rehumidification but comes back to its initial value, and irreversibility means that the parameter does not come back to its initial value after the drying and re-humidification cycle.
} 


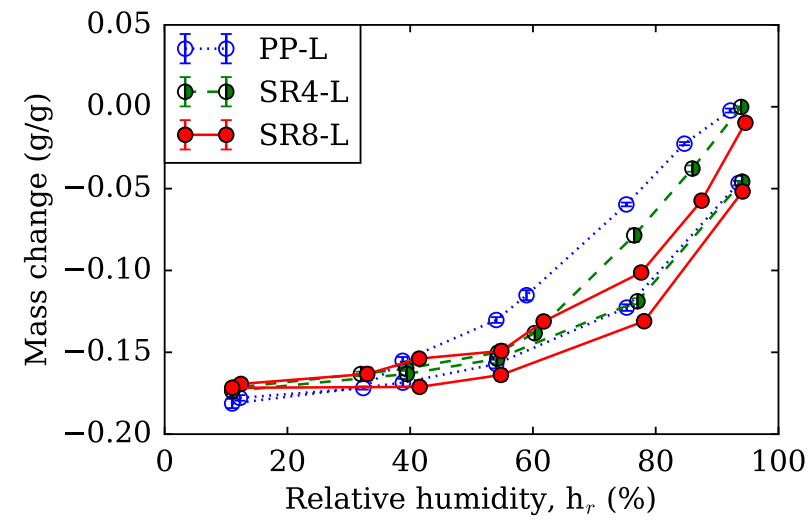

Figure 2: Mass change of cement paste with and without SRA.

comparable for the two cement pastes. On the re-humidification branch, cement pastes regained water according to similar trends, except for the cement paste that contains $8 \%$ of SRA, which regains less mass than the plain paste and the paste that contains $4 \%$ of SRA. Several studies have reported the impact of the SRA on mass loss [5, 6, 13]. Weiss et al. [6] also found that for drying at RH $>50 \%$, samples containing SRA lost more or roughly the same amount of mass compared with plain pastes; this effect was attributed to the ability of the SRA to reduce surface tension. Bentz et al. [5] found that the rate of evaporation of water was also influenced by the addition of SRA in both bulk water and evaporable water in the cement paste.

The length change isotherms for cement pastes during drying and subsequent re-humidification are shown in Figure 3 For plain pastes, drying shrinkage de275 creased linearly with decreasing relative humidity. At RH $<54 \%$, length changes in the samples during the first drying and re-humidification were nearly identical: little to no hysteresis was observed. When the plain paste was re-humidified to $>54 \%$, not all shrinkage was recovered: an irreversible shrinkage can be observed. For $\mathrm{RH}<75 \%$, the drying shrinkage for pastes containing SRA was consistently lower than for the plain paste. The extent of shrinkage reduction by SRA (i.e., the difference between the drying shrinkage of the pastes contain- 


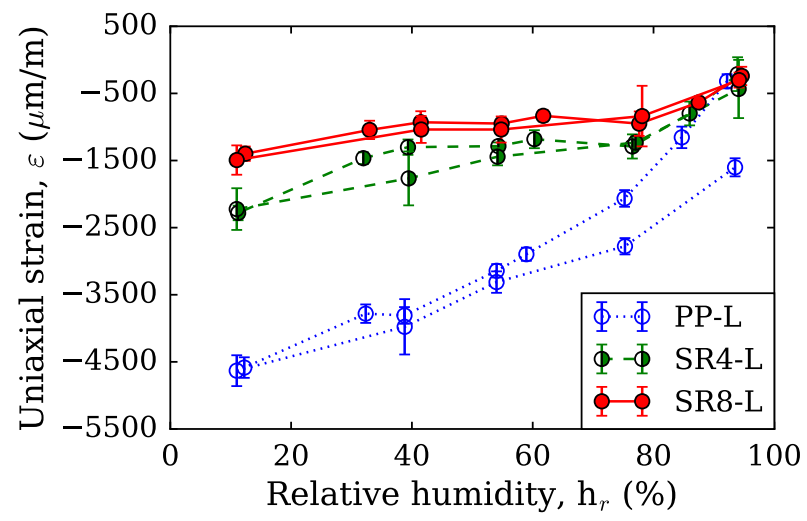

Figure 3: Length change of cement pastes with and without SRA.

ing SRA and that of the plain paste) was smaller for $\mathrm{RH}>75 \%$ than for $\mathrm{RH}$ $<75 \%$. Moreover, we observed a plateau in the drying shrinkage for relative humidities ranging from 33\%-75\% for pastes containing SRA. Furthermore, at the $95 \%$ relative humidity re-humidification step, samples with SRA roughly returned to their initial length (length before drying). When the drying shrinkage isotherms were plotted in terms of relative humidity, we observed a nearly closed loop for pastes containing SRA, while those samples do not regain all their mass when re-humidified to a relative humidity of $95 \%$ after drying at a relative humidity of $11 \%$.

In Figure 4 the drying shrinkage is plotted in terms of mass change for the plain paste and for the pastes containing $4 \%$ and $8 \%$ of SRA. The results show that, regardless of the humidity change path, the data points for the plain pastes and the data points for pastes containing SRA drew a line without hysteresis (hereafter we call this line as a master curve). The strain of the plain paste evolved linearly with the mass change. This phenomenon was also reported by Hansen [21] for the drying branch, and by Maruyama [22, who described a linear behavior for plain pastes at various water to cement ratios on both the drying and re-humidification branches.

${ }_{300}$ The shrinkage strain of the pastes containing SRA evolved with the relative 


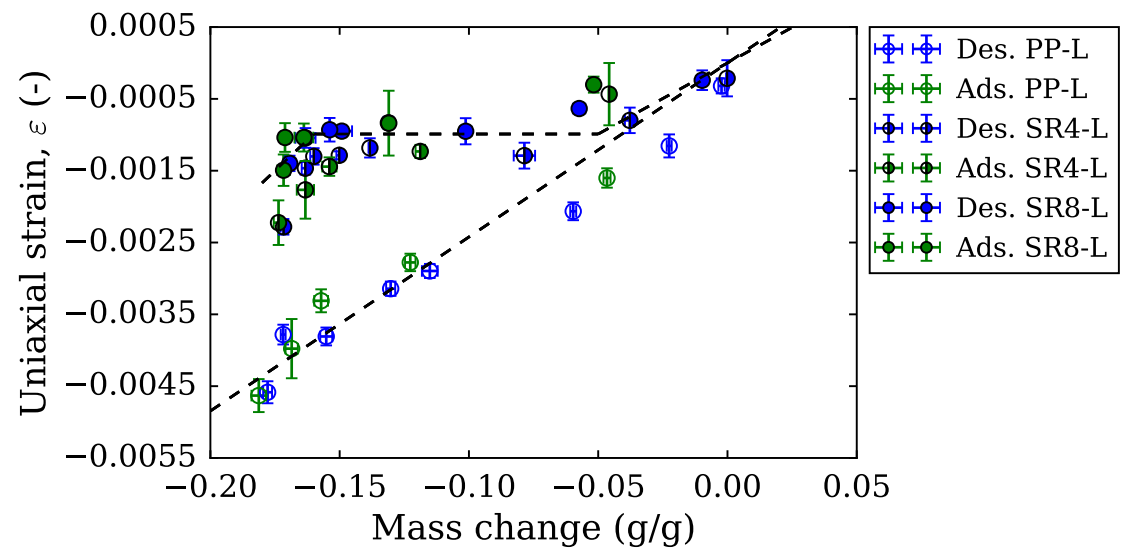

Figure 4: Strains with respect to relative mass changes for cement pastes with various SRA contents after drying (indicated by blue symbols) and re- humidification (indicated by green symbols).

humidity according to three regimes. The first regime was observed when the relative mass loss was less than $0.05 \mathrm{~g} / \mathrm{g}$, during which the strain evolved linearly with the relative mass change. The second regime was observed for relative mass losses between $0.05 \mathrm{~g} / \mathrm{g}$ and $0.15 \mathrm{~g} / \mathrm{g}$, during which the mass loss did not generate any additional shrinkage. In the third regime, the relative mass loss was larger than $0.15 \mathrm{~g} / \mathrm{g}$, and the sample shrank when the mass decreased.

\subsection{Length change and mass change isotherms during short-term drying and re-humidification}

In this section, we investigate the drying shrinkage behavior of samples that were not dried prior to measurements (denoted as 'non-pre-dried') and of samples that were subject to a long drying period at a relative humidity of $11 \%$ prior to measurements (denoted as 'pre-dried'). The short-term drying length and mass change measurements for the various cement pastes are shown in Figure 5 for the non-pre-dried samples and in Figure 6 for the pre-dried samples.

For the non-pre-dried plain paste, shown in Figure 5 (a), a significant fraction of the shrinkage occurred at $\mathrm{RH}>35 \%$. The length change upon re- 
humidification depended linearly on the relative humidity. Moreover, the length change observed on the re-humidification path for $\mathrm{RH}>35 \%$ was lower than the length change observed on the drying path: the length change was irreversible for $\mathrm{RH}>35 \%$. For pastes containing SRA, on the drying path, the length change was lower in the $\mathrm{RH}$ range of $35 \%-75 \%$ than for $\mathrm{RH}>75 \%$ or $\mathrm{RH}<35 \%$. The hysteresis of the length change for the samples containing SRA during drying and re-humidification was smaller than that of the plain paste. The relative mass change of the plain paste, displayed in Figure 5 (b), depended linearly on relative humidity during drying. During re-humidification, we also observed linear behavior for relative humidities between $5 \%$ and $75 \%$. Moreover, the mass change followed different paths during drying and re-humidification but exhibited a closed loop. For samples containing SRA, the mass changes evolved differently during drying and re-humidification. on the drying branch, the mass loss was larger for $\mathrm{RH}>55 \%$ than for $\mathrm{RH}<55 \%$; by contrast, on the re-humidification branch, the samples regained most of their mass for $\mathrm{RH}$ $>75 \%$.

The results confirm that SRA can significantly reduce drying shrinkage. When a sample is dried at a relative humidity of $5 \%$, the presence of SRA resulted in a $63 \%$ reduction in the short-term drying shrinkage compared with plain paste. This is consistent with the shrinkage results for samples under long-term drying .

For pre-dried cement pastes, the length and mass changes with respect to relative humidity are shown in Figure 6. The length change during drying and re-humidification may be considered linear with respect to relative humidity. The length changes for the pre-dried plain cement paste and for the cement pastes containing SRA were similar and significantly smaller than for the nonpre-dried cement pastes. For the mass change in the plain paste, a sharp mass loss occurred when the relative humidity decreased from $95 \%$ to $75 \%$, followed 345 by a steady mass loss between $75 \%$ and $35 \%$, and a larger mass loss from $35 \%$ to $5 \%$. For the pastes containing SRA, the mass change decreased linearly with decreasing relative humidity down to $55 \%$, at which point a change in slope 
(a)

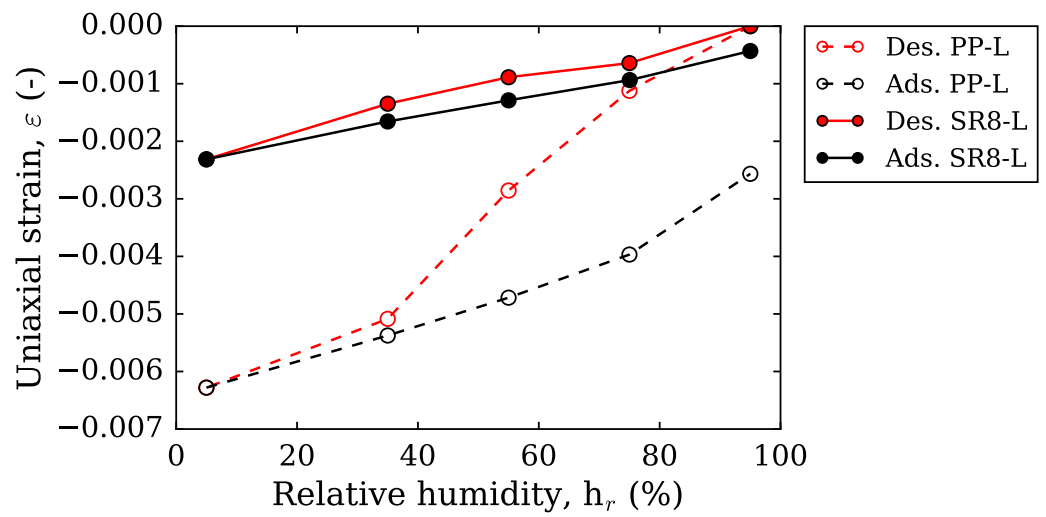

(b)

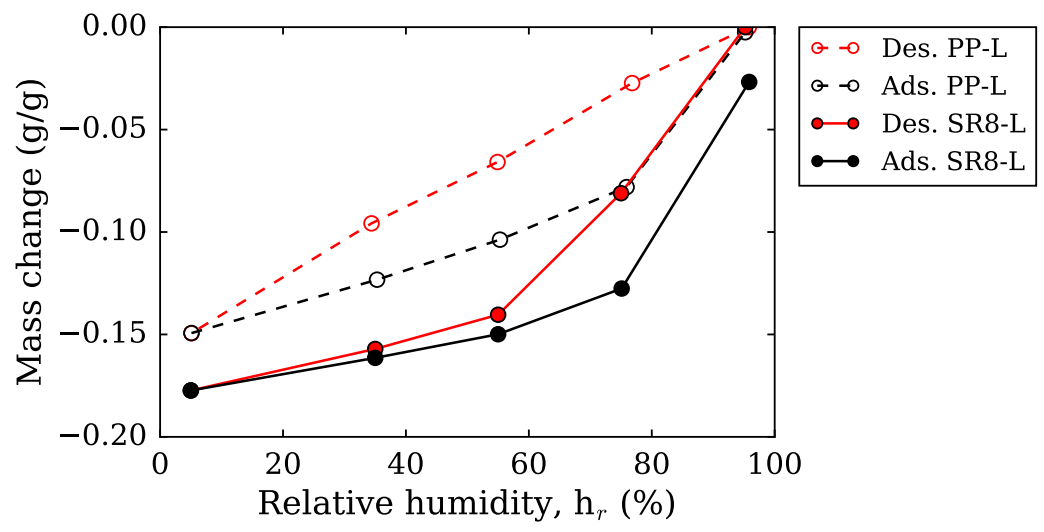

Figure 5: Short-term drying length change (a) and mass change (b) of plain paste (PP-L) and paste containing $8 \%$ SRA (SR8-L). 
occurs. On the re-humidification branch, both the plain cement paste and the paste containing SRA regained water linearly for $\mathrm{RH}<75 \%$. At $\mathrm{RH}>75 \%$, both cement pastes with and without SRA regained a significant fraction of the water. The mass change formed a closed loop for drying and subsequent re-humidification.

\subsection{Post-hydration addition of $S R A$}

When SRA was added after hydration (sample PP-L-SRA), the amount of SRA in the cement paste after measurements was assessed by estimating the organic carbon content in the sample: the samples contained an equivalent TOC amount of $4.5 \mathrm{~g} \pm 0.3 \mathrm{~g}$ per $100 \mathrm{~g}$ of cement paste. Given the mix design, this amount corresponds to $6.9 \%$ in mass of cement.

Results for the length and mass changes in the plain paste sample with posthydration SRA added(sample PP-L-SRA) are shown in Figure 7. On the same plot, results obtained for the plain paste (sample PP-L) and for the $8 \%$ SRA (pre-hydration addition) paste (sample SR8-L) are displayed as a comparison. The results show that SRA reduces the drying shrinkage of the sample even when added after hydration. The reduction was more significant in the relative humidity range from $75 \%$ down to $55 \%$ than in the range of relative humidities below $55 \%$ or higher than $75 \%$. The mass change was also affected by the SRA added after hydration. On the desorption branch, the mass loss of the cement paste with post-hydration SRA added was larger than that for the plain paste in the relative humidity range of 55\%-35\% and comparable to that of the 370 plain paste at $\mathrm{RH}=75 \%$ and $\mathrm{RH}=5 \%$. However, on the adsorption branch, the sample with SRA added after hydration regained water similarly to the plain paste. This observation is an indicator that the SRA significantly impacts how the water is removed from the pore network of the cement paste.

This finding suggests that SRA could be used as curing agent for cement paste by adding it after the hydration/hardening. This way, the drying shrinkage could be reduced while also avoiding drawbacks observed when adding the SRA before hydration, such as reduction of the hydration degree or modification of 
(a)

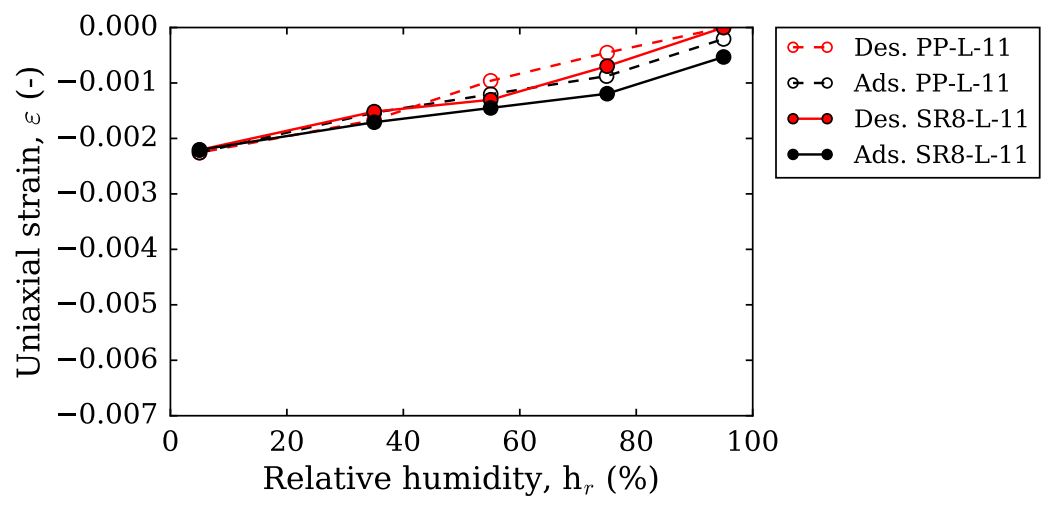

(b)

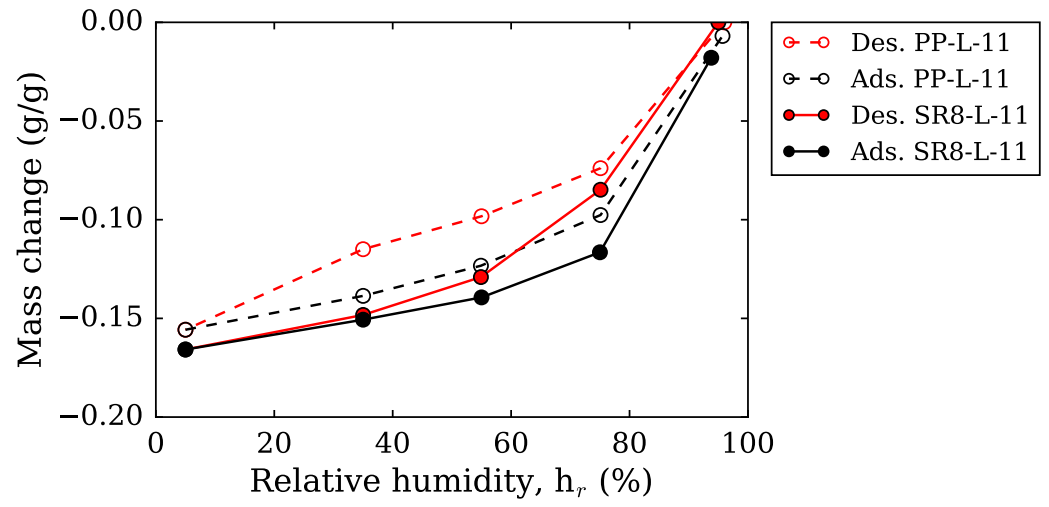

Figure 6: Short-term drying length change (a) and mass change (b) of pre-dried plain paste (PP-L) and pre-dried paste containing $8 \%$ of SRA (SR8-L). 
(a)

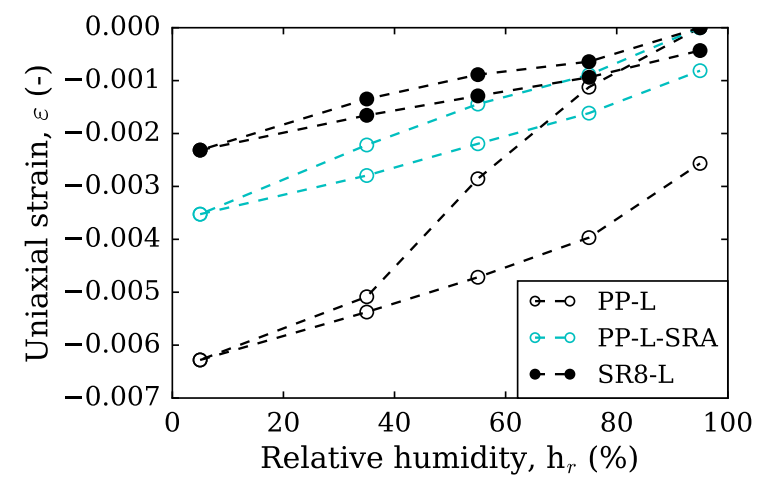

(b)

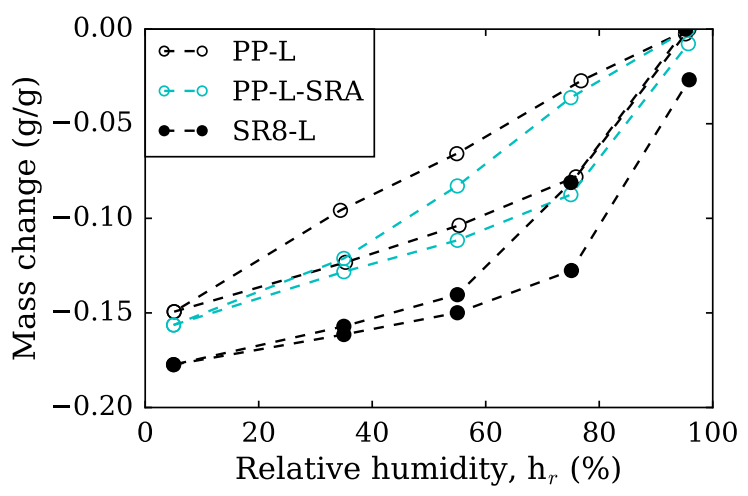

Figure 7: Short-term drying length change (a) and mass change (b) of cement paste without SRA (sample PP-L), with SRA added after hydration (sample PP-L-SRA) and with $8 \%$ of SRA added before hydration (sample SR8-L). 
the pore structure. Bentz [23] tested the addition of SRA as a curing agent to mortar by spraying an SRA solution at concentrations of $10 \%$ and $20 \%$. In this study, they investigated the availability of water for hydration in these cement pastes relative to a plain paste under identical relative humidities. Dang et al. 24] later investigated the virtues of using SRA as a curing agent in mortar. Their results confirm that the addition of SRA as a curing agent lowers the drying shrinkage.

3.4. Ability of SRA to reduce the drying shrinkage: dependency on relative humidity

In our study, we used both long-term and short-term measurements to confirm that SRA can reduce the first drying shrinkage. Moreover, both the longterm and short-term measurements showed that the SRA significantly reduces the irreversibility of drying shrinkage and even suppresses it in some cases. The ability of the SRA to reduce the drying shrinkage was highest in the relative humidity range of $33 \%-75 \%$, in which the drying shrinkage of the cement paste is almost constant even when the mass of the sample decreases: mass loss and shrinkage are not correlated in this range of relative humidity.

\subsection{On the irreversibility of drying shrinkage}

The cement pastes containing SRA exhibited an almost reversible length change between the first drying and subsequent re-humidification, in contrast to the plain paste, which did not recover its initial length after the first drying and re-humidification. In addition, short-term drying measurements show that while prolonged drying of the plain paste significantly impacted its drying shrinkage and mass loss (as shown in Figure 5 compared to Figure 66), the pastes containing SRA were slightly impacted by this prolonged drying.

The causes of this irreversibility for the plain cement paste may be linked to a decrease in pore volume [15], a re-arrangement of the pore structure upon drying [25, 26], and the creation of silicates bonds in C-S-H [27, 26]. Recently, Gartner et al. 28] suggested that the irreversibility originates from the bridging 
of calcium ions in C-S-H sheets, leading to their cross-linking during the drying process, and eventually to a definitive reduction in space between inter-layers. The rearrangement of the pore structure after drying was investigated by studying the pore structure of the cement pastes after drying [29, 30, 31, 32]; these studies showed that typically, the specific surface area tends to decrease during long drying processes. An investigation of cement paste drying by ${ }^{1} \mathrm{H}$ NMR also showed that the spacing between the C-S-H layers decreased after drying [33], confirming that drying results in the re-organization of pore space in the cement paste.

The effect of the SRA on the irreversible drying shrinkage may be related to interference with this potential pore structure re-arrangement and with the polymerization of the C-S-H. However, several studies also showed that upon re-humidification, the reported changes in the surface area are reversible if rehumidification is performed up to a high relative humidity or if the sample is re-saturated [30, 34, 35, 36. Hence, the link between irreversibility and evolution of the pore structure is still unclear. Also, it should be noted that these studies did not investigate the evolution of the specific surface area during a drying and re-humidification cycle. These changes may exhibit a hysteresis when plotted in terms of relative humidity. Another potential cause for the irreversibility of drying shrinkage is the ink- bottle effect that occurs during drying. The ink-bottle effect causes a hysteresis of the degree of saturation (the ratio of the volume of liquid water to the total volume of pores), when the degree of saturation is plotted in terms of the relative humidity. Assuming that shrinkage at a high relative humidity is governed by capillary effects according to Coussy's model [37, the hysteresis of the degree of saturation may lead to an irreversibility in the shrinkage. At a high relative humidity, on the drying branch, the mass loss of the plain paste was greater for the long-term drying measurements than for the short-term drying measurements. On the re-humidification branch, the 435 plain pastes regained water in a similar manner to both short-term and longterm drying measurements. This observation indicates that at a given relative humidity, the difference in the saturation degree between the drying branch and 


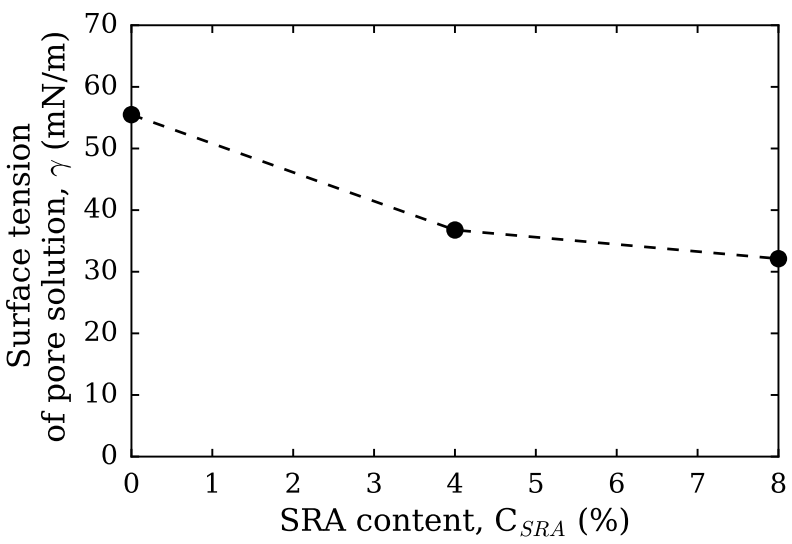

Figure 8: Surface tension of the pore solutions extracted from cement pastes with respect to SRA content, measured by the Wilhelmy plate method.

the re-humidification branch may be larger for short-term drying measurements than for long-term drying measurements (assuming that the total volume of pores is constant). As a result, irreversible shrinkage may be more significant for short-term drying measurements than for long-term drying measurements.

\section{Influence of SRA on pore solution properties}

To shed light on the performance of SRA, in this section we examine the influence of the SRA on the properties of the pore solution (extracted and nonextracted solutions).

\subsection{Properties of extracted pore solutions}

\subsubsection{Surface tension of solution}

Figure 8 displays the surface tension measured using the Wilhelmy plate method for extracted pore solutions from the cement pastes containing different amounts of SRA. The results confirmed that the surface tension of the pore solution decreased in the presence of SRA, since the surface tension of the 


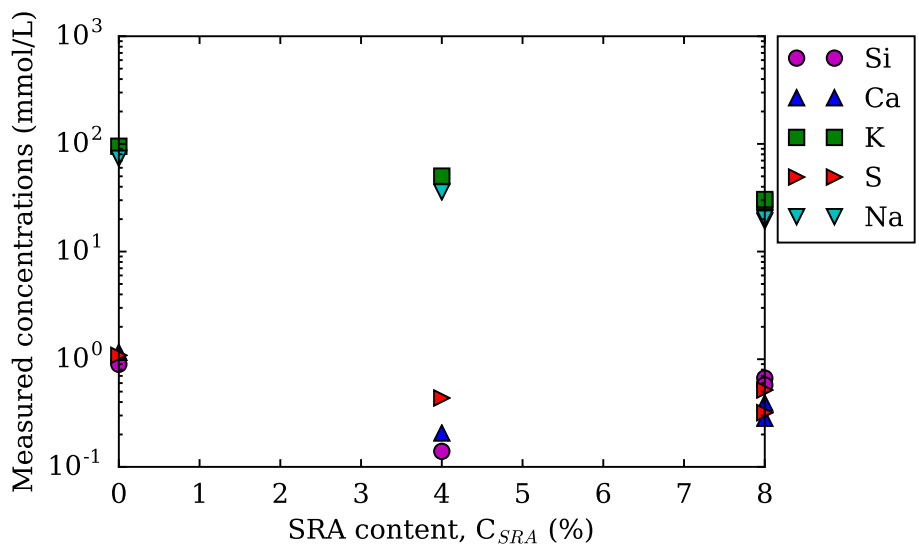

Figure 9: Measured concentrations of pore solutions extracted from the cement pastes with respect to SRA content.

pore solution from the paste containing $8 \%$ of SRA (SR8-L) decreases by $42 \%$ relatively to that of the plain paste.

\subsubsection{Composition of solutions}

The ionic composition of the extracted pore solutions is displayed as a function of SRA content in Figure 9. The calcium concentrations in the pore solution were small (i.e. lower than $10 \mathrm{mmol} / \mathrm{L}$ ) in the extracted pore solutions. This can be attributed to the near-saturation of calcium with regards to presence of portlandite in the system [20, 38. The results show that sulfates are present in relatively minor concentrations compared with potassium in the pore solutions. This may be because sulfates are incorporated in the solid phase by hydrates (e.g. ettringite). The $\mathrm{pH}$ of the solution was estimated using $\mathrm{pH}$ strips; we observed no significance difference between solutions extracted from plain pastes and pastes containing SRA.

The results show that the absolute concentration of alkalis (potassium and sodium) decreased consistently with an increasing SRA content. This is consistent with the results of a study by Rajabipour et al., which showed that the concentrations in $\mathrm{K}^{+}$and $\mathrm{Na}^{+}$in extracted pore solutions were lower in cement 
pastes containing SRA than in plain pastes [39]. According to this study, this observation could be related to the action of the SRA on the solubility of alkali sulfates; the solubility of alkali sulfates decreases, resulting in a reduced rate of dissolution.

\subsection{Properties of the pore solution: cavitation pressure}

Cavitation occurs when the liquid phase is under significant tensile stress; 475 at this point, the liquid reaches an unstable state and a phase change occurs, converting liquid water into vapor. This phenomenon may occur when a pore is constricted, i.e., when a pore is connected to the outside through an entry whose radius is smaller than a critical threshold. In this case, the large negative pressure required for cavitation can be reached before the meniscus can recede in the constriction. Cavitation can manifest itself on the water isotherm by a marked jump on the desorption branch. This jump was observed at a relative pressure of 0.35 [40, 41]. When water cavitates in the hardened cement paste, the water is no longer a capillary condensate. Consequently, the capillary forces no longer occur at relative humidities that correspond to capillary pressures larger than the cavitation pressure.

To investigate the impact of SRA on the cavitation pressure of the pore solution during cement paste drying and re-humidification, we examined the water vapor adsorption and desorption isotherms of our cement pastes. The sorption isotherms of the cement pastes without SRA (sample PP-L), with $4 \%$ SRA (sample SR4-L), and with 8\% SRA (sample SR8-L) are displayed in Figure 10. The presence of SRA in the cement paste results in an increase in the relative humidity at which cavitation occurs, from a relative humidity of about $35 \%$ up to a relative humidity of about $65 \%$. The effect of SRA on the cavitation pressure may at least partly explain its ability to reduce the shrinkage observed during drying; capillarity-induced tensile stresses may be released at a higher relative humidity in the presence of SRA compared with the plain paste.

To further investigate the impact of the SRA on water cavitation during desorption, we measured the sorption isotherms for zeolite Z40-HW [42, with 


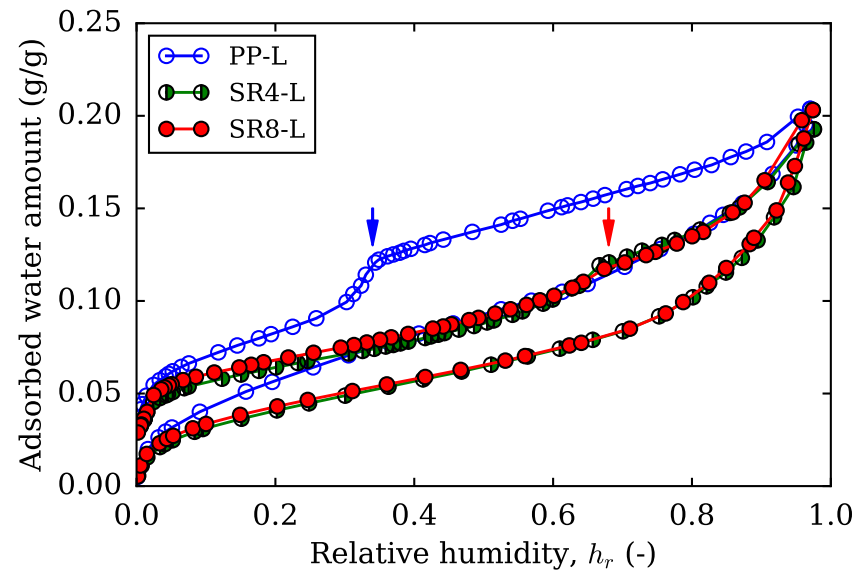

Figure 10: Sorption isotherm of cement paste without SRA (sample PPL), with $4 \%$ of SRA (sample SR4-L) and with $8 \%$ of SRA (sample SR8-L). Cavitation occurs at the relative humidity indicated with arrows.

and without SRA. The water sorption isotherms of these two systems are shown in Figure 11. The addition of SRA resulted in a shift in the relative humidity at which a jump is observed on the desorption branch. The relative humidity at which this jump could be observed was similar for the desorption branches of both cement pastes and zeolite, indicating that the relative humidity at which this characteristic jump occurs is a property of the fluid rather than the pore structure. This shift in $\mathrm{RH}$ in presence of SRA has been reported for cement pastes with SRAs [16] (based on alcohol-ethylene oxide polymer with number of ethylene oxide groups of at least 2), and for zeolites with an SRA based on alcohol-ethylene oxide polymers with a better hydrophilic-lipophilic balance [40].

For both the cement pastes and the zeolites, the isotherms (displayed in Figures 10 and 11, respectively) changed in the presence of SRA. For the cement paste, at $\mathrm{RH}<95 \%$, the adsorbed volumes were lower for the pastes containing the SRA than for the plain paste, but the total adsorbed volume in the cement pastes did not depend on the content in SRA. By contrast, for zeolites, for 


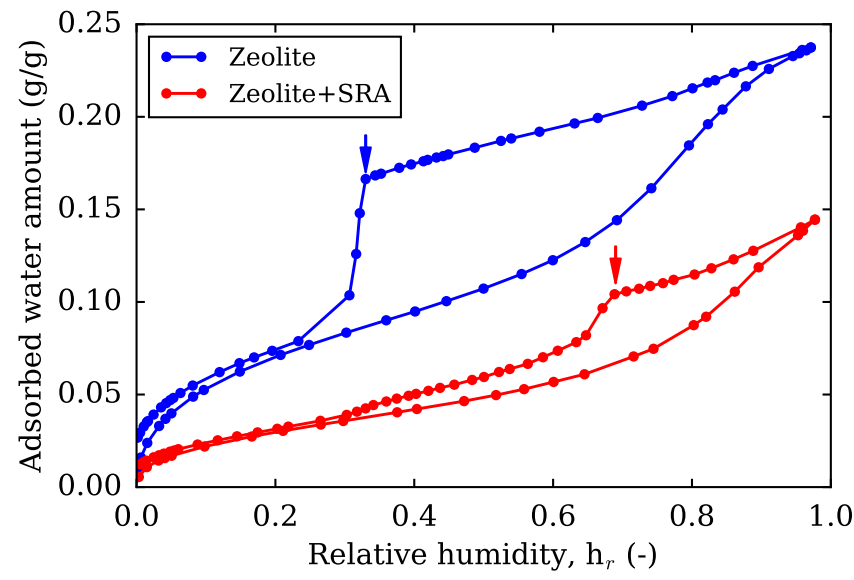

Figure 11: Water sorption isotherms of a zeolite and zeolite+SRA. Arrows indicate the relative humidity at which cavitation occurs. Credits to Jiří Rymeš (Graduate School of Environmental Studies, Nagoya University) for water adsorption measurements on plain zeolite without SRA.

the entire range of investigated relative humidities, the adsorbed volumes were lower for the zeolite containing the SRA than for the plain zeolite. We modeled the adsorption isotherm at a low relative humidity using the Brauner-EmmettTeller (BET) model [3], and assuming a cross-sectional area for adsorbed water of $0.114 \mathrm{~nm}^{2}$ [4], to determine the specific surface areas for both preparation methods: $242 \mathrm{~m}^{2} / \mathrm{g}$ for the zeolite without SRA and of $105 \mathrm{~m}^{2} / \mathrm{g}$ for the zeolite with SRA. For the zeolites, the decrease in the specific surface area in the presence of SRA indicates that the SRA may hinder some of the adsorption sites. For cement pastes, the decrease in specific surface area (from $193 \mathrm{~m}^{2} / \mathrm{g}$ for the plain paste to $145 \mathrm{~m}^{2} / \mathrm{g}$ for the cement pastes containing SRA) may also be linked to a retarded cement paste hydration in the presence of SRA, in addition to a potential interference with adsorption sites [4, 7, 12, 19]. In our study, we found that SRA retarded hydration from an early stage, an effect that could be observed after one year of hydration (results not shown). After one year, hydration still progresses for the pastes with SRA as well as for the plain ${ }_{530}$ paste. 
The impact of SRA on the surface area may indicate that the SRA molecules may be present in the C-S-H interlayer and in the gel porosity of the cement pastes, thus hindering adsorption sites. The potential adsorption of SRA on solid surfaces could impact the surface stresses induced by drying.

\subsection{Leaching of SRA from cement pastes in saturated conditions}

In Figure 12 the measured concentration $C_{\text {meas }}$, which was calculated under the assumption that none of the SRA adsorbs to the hydrates (i.e., SRA can be fully leached out of the paste). With an increasing number of cycles, the concentration of organic carbon in the solution decreases. Moreover, the measured concentration of organic carbon was consistent with the theoretical concentration, which was calculated by assuming that no adsorption occurred. The measured organic carbon concentrations were low, indicating that organic carbon was completely depleted, and that SRA can be fully leached out of the cement paste during the leaching experiments. Furthermore, a significant amount of SRA was removed during the first cycle. For the last cycles of some cement pastes, the theoretical organic concentrations had negative values, meaning that more organic carbon was released from the cement paste than expected. Such negative values may be attributed to the accumulation of errors during the organic compound concentration calculations. Indeed, error bars for the SR8-L data are of the same order of magnitude as the variation of these negative values. We concluded that in saturated conditions, the SRA was not trapped within the cement paste pores.

\section{Role of SRA in reducing drying shrinkage}

\subsection{Impact of SRA on capillary forces}

The reduction of the capillary forces in the presence of SRA may be caused by the reduction in the surface tension of the pore solution in the presence of SRA and by the potential reduction in the saturation degree at a given relative humidity. In fact, when the cement paste was dried to a given relative humidity, 


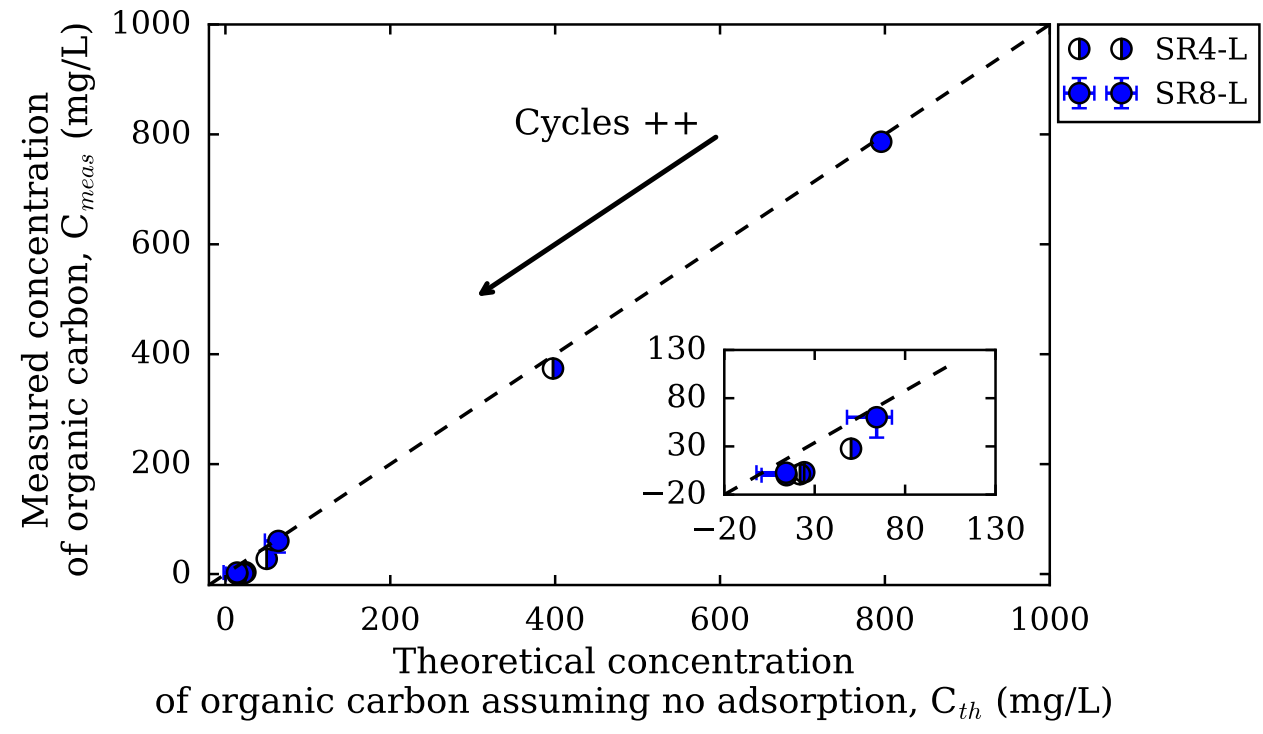

Figure 12: Amount of organic carbon originating from SRA leached from the cement pastes as a function of the theoretical organic carbon expected when assuming no SRA adsorption. Plotted error bars for SR8-L correspond to the maximum and minimum observed values for the set of three measurements. The inset plot is an enlarged view of the low region of recorded concentrations. 
the reduction in the surface tension, shown in Figure 8, resulted in a reduction in the capillary pressure. The mass loss was larger in cement pastes containing SRA than in the plain paste, which may also indicate that the saturation degree is lower for cement pastes containing SRA than for plain pastes. Also, the SRA lowered the cavitation pressure for water. Indeed, the relative humidity at which water cavitation occurred was higher for pastes with SRA than for the plain paste, which resulted in a reduced relative humidity range over which capillary forces occur.

\subsection{Evolutions of surface properties in presence of $S R A$}

Water is often assumed to wet the cement pastes. However, the SRA could change the surface properties of the cement paste and modify its wettability. The results of the long-term drying shrinkage isotherms and mass change isotherms show that mass loss and drying shrinkage were not correlated for relative humidities ranging from $33 \%-75 \%$, since the removal of water in this relative humidity range does not induce a length change. This range of relative humidity is the same as the range over which Gibbs-Bangham type surface effects are considered to be dominant [45]. Furthermore, in the presence of SRA, water cavitation occurred at a relative humidity of $70 \%$, which suggests that water was only present in the cement paste as adsorbed water on surfaces or in micropores below this relative humidity. This observation raises questions about how SRAs modify the properties of solid surfaces, and how this possible modification leads to a reduction in drying shrinkage.

Organic molecules are known to modify the wettability of the surface of porous materials. The presence of organic molecules in soils causes their water repellency [46]. When grafted with organic molecules, silica gel becomes hydrophobic and drying shrinkage of these systems is reduced. This could be beneficial for industrial production, since this method can prevent cracking during drying [47, 48, 49, 50]. The link between the changes in surface properties and shrinkage for these materials can be explained by the elimination of the irreversible shrinkage that is caused by chemical cross-linking between adjacent 
silica clusters [48, 50] and the reduction in the capillary forces from a decreased solution surface tension [49]. The SRA may adsorb to the surfaces of cement pastes during drying, forming hydrophobic patches. This may also explain the reduced drying kinetics observed by Bentz et al. [5]. According to their work, a drying front develops during the cement paste drying process. In hydrophobic porous materials, a drying front develops at the first stage of drying, whereas in hydrophilic porous materials, this drying front is observed at later stages [51. The adsorption of SRA may minimize the changes in surface energy during the drying process; assuming that the Gibbs-Bangham mechanism properly describes the impact of surface effects on length change, reducing the surface energy makes it possible to reduce the drying shrinkage.

The adsorption of the SRA may also be promoted during material drying. In this study, we performed leaching experiments on cement pastes in a synthetic pore solution, showing that the SRA does not get adsorbed in saturated conditions and can be leached out of the cement pastes. However, we could not rule out SRA adsorption in partially saturated conditions.

\section{Conclusions}

In this work, we investigated the drying shrinkage and the mass change isotherms of cement pastes containing various concentrations of an SRA (hexylene glycol) using both long-term and short-term drying measurements. The influence of the SRA on the drying shrinkage was investigated by examining the impact of the SRA on the properties of the pore solution and on the reversible and irreversible drying shrinkage.

The long-term drying measurements showed that the SRA had the highest performance in the mid-range for relative humidities. In the range of 33\%-77\%, the shrinkage of the cement pastes containing SRA was not correlated with the mass loss and the shrinkage-mass relation curve exhibits a plateau. The SRA also impacted the mass loss. When samples were dried at a high relative humidity, the mass loss for cement pastes containing SRA was larger than that 
of the plain paste. During re-humidification, the drying shrinkage isotherms of the pastes containing the SRA formed a closed loop and a smaller hysteresis than the plain paste. The addition of SRA suppressed the irreversibility of drying shrinkage. Short-term drying measurements confirm these trends. Also, irreversible shrinkage was larger in short-term drying measurements than in long-term drying measurements. The pre-drying and the addition of SRA led to a lower irreversibility and to a reduction in the observed shrinkage during a cycle of drying and dehumidification compared with the plain paste. The SRA also reduced the drying shrinkage when it was added after the cement paste hardened, which indicates that the impact of the SRA on the microstructure is not a major mechanism for the action of the SRA.

The action of the SRA on the pore solution and the drying shrinkage isotherms provide insight into the action of the SRA on the drying shrinkage. Alkalis were depleted in presence of the SRA. The reduction in the surface tension of the pore solution was confirmed through an analysis of the extracted pore solutions. Moreover, the SRA increased the relative humidity at which water cavitates during the drying process. Below this relative humidity, water was adsorbed on the pore walls or in the micropores of the cement paste. Therefore, the SRA acts on the capillary forces not only by reducing the capillary pressure through a reduction in the surface tension, but also by reducing the relative humidity range over which capillary forces occur. Also, in saturated conditions, the SRA can be fully leached out of the cement pastes and therefore does not get adsorbed on the cement hydrates. However, we cannot exclude the possibility that the SRA may also change the properties of the solid surfaces by getting adsorbed to the pore walls for relative humidities smaller than $75 \%$, in the range at which a plateau can be observed on the drying shrinkage isotherm. Therefore, the surface stresses may be reduced in the presence of SRA. This potential adsorption ${ }_{645}$ may also hinder the re-arrangement of the pore structure, which could impact the irreversibility of the drying shrinkage. 


\section{Acknowledgments}

This work is dedicated to Ellis Gartner, who was one of the initiators of this project and whose kindness and expertise we miss. We thank Abudushalamu

Aili for his help in the final editing of the manuscript.

[1] E.-I. Tazawa, S. Miyazawa, Influence of cement and admixture on autogenous shrinkage of cement paste, Cement and Concrete Research 25 (2) (1995) 281-287. doi:10.1016/0008-8846(95)00010-0.

[2] D. P. Bentz, O. M. Jensen, Mitigation strategies for autogenous shrinkage cracking, Cement and Concrete Composites 26 (6) (2004) 677-685. doi: 10.1016/S0958-9465(03)00045-3.

[3] B. Rongbing, S. Jian, Synthesis and evaluation of shrinkage-reducing admixture for cementitious materials, Cement and Concrete Research 35 (3) (2005) 445-448. doi:10.1016/j.cemconres.2004.07.009

[4] G. Sant, F. Rajabipour, P. Lura, J. Weiss, Examining time-zero and early age expansion in pastes containing shrinkage reducing admixtures (SRA's), in: Advances in Concrete Through Science and Engineering. In : Proceedings of the RILEM International Symposium, Quebec, 2006.

[5] D. P. Bentz, M. Geiker, K. Hansen, Shrinkage-reducing admixtures and early-age desiccation in cement pastes and mortars, Cement and Concrete Research 31 (7) (2001) 1075-1085. doi:10.1016/S0008-8846(01) 00519-1

[6] J. Weiss, P. Lura, F. Rajabipour, G. Sant, Performance of shrinkagereducing admixtures at different humidities and at early ages, ACI Materials Journal 105 (5) (2008) 478-486. doi:10.14359/19977.

[7] J. Saliba, E. Rozière, F. Grondin, A. Loukili, Influence of shrinkagereducing admixtures on plastic and long-term shrinkage, Cement and Concrete Composites 33 (2) (2011) 209-217. doi:10.1016/j.cemconcomp. 2010.10 .006 
[14] K. J. Folliard, N. S. Berke, Properties of high-performance concrete containing shrinkage-reducing admixture, Cement and Concrete Research 27 (9) (1997) 1357-1364. doi:10.1016/S0008-8846(97)00135-X.

[15] R. A. Helmuth, D. H. Turk, The reversible and irreversible drying shrinkage of hardened portland cement and tricalcium silicate pastes, Portland Cement Association Journal Research and Development Laboratories 9 (2) (1967) 8-21.

[16] I. Maruyama, E. Gartner, K. Beppu, R. Kurihara, Role of alcohol-ethylene oxide polymers on the reduction of shrinkage of cement paste, Cement and 
Concrete Research 111 (2018) 157-168. doi:10.1016/j.cemconres.2018. 05.017

[17] I. Maruyama, G. Igarashi, Cement Reaction and Resultant Physical Properties of Cement Paste, Journal of Advanced Concrete Technology 12 (2014) 200-213. doi:10.3151/jact.12.200.

[18] J. Bisschop, F. K. Wittel, Contraction gradient induced microcracking in hardened cement paste, Cement and Concrete Composites 33 (4) (2011)

口466-473. arXiv:arXiv:1509.04964v1, doi:10.1016/j.cemconcomp. 2011.02 .004

[19] D. P. Bentz, Influence of shrinkage-reducing admixtures on early-age properties of cement pastes, Journal of Advanced Concrete Technology 4 (3) (2006) 423-429. doi:10.3151/jact.4.423

[20] J. Duchesne, M. A. Bérubé, Evaluation of the validity of the pore solution expression method from hardened cement pastes and mortars, Cement and Concrete Research 24 (3) (1994) 456-462.

[21] W. Hansen, Drying Shrinkage Mechanisms in Portland Cement Paste, 口 Journal of the American Ceramics Societey 70 (5) (1987) 323-328. doi: 10.1111/j.1151-2916.1987.tb05002.x.

[22] I. Maruyama, Multi-Scale Review for Possible Mechanisms o f Natural Frequency Change of Reinforced Concrete Structures under an Ordinary Drying Condition, Journal of Advanced Concrete Technology 14 (2016) 691705. doi:10.3151/jact.14.691.

[23] D. P. Bentz, Curing with shrinkage-reducing admixtures, Concrete international (2005) 55-60.

[24] Y. Dang, J. Qian, Y. Qu, L. Zhang, Z. Wang, D. Qiao, X. Jia, Curing cement concrete by using shrinkage reducing admixture and curing compound, Construction and Building Materials 48 (2013) 992-997. doi:10.1016/j.conbuildmat.2013.07.092. 
[25] R. F. Feldman, P. J. Sereda, A model for hydrated Portland cement paste as deduced from sorption-length change and mechanical properties, Matériaux et Construction 1 (6) (1968) 509-519. doi:10.1007/BF02473639.

[26] H. M. Jennings, Refinements to colloid model of C-S-H in cement: CM-

[30] G. G. Litvan, R. E. Myers, Surface area of cement paste conditioned at various relative humidities, Cement and Concrete Research 13 (1) (1983) 49-60. doi:10.1016/0008-8846(83)90127-8

[31] I. Maruyama, Y. Nishioka, G. Igarashi, K. Matsui, Microstructural and

[32] I. Maruyama, N. Sakamoto, K. Matsui, G. Igarashi, Microstructural changes in white Portland cement paste under the first drying process evaluated by WAXS, SAXS, and USAXS, Cement and Concrete Research 91 (2017) 24-32. doi:10.1016/j.cemconres.2016.10.002. 
[33] I. Maruyama, T. Ohkubo, T. Haji, R. Kurihara, Dynamic microstructural evolution of hardened cement paste during first drying monitored by $1 \mathrm{H}$ NMR relaxometry, Cement and Concrete Research 122 (2019) 107-117. doi:10.1016/j.cemconres.2019.04.017.

[34] D. Pearson, A. J. Allen, A study of ultrafine porosity in hydrated cements using small angle neutron scattering, Journal of Materials Science 20 (1) (1985) 303-315. doi:10.1007/BF00555924.

[35] D. N. Winslow, S. Diamond, Specific surface of hardened Portland cement paste as determined by smallangle XRay scattering, Journal of the Amer-

ㅁ ican Ceramic Society 57 (5) (1974) 193-197. doi:10.1111/j.1151-2916. 1974.tb10856.x

[36] V. Baroghel-Bouny, Water vapour sorption experiments on hardened cementitious materials. Part I: Essential tool for analysis of hygral behaviour and its relation to pore structure, Cement and Concrete Research 37 (3) (2007) 414-437. doi:10.1016/j.cemconres.2006.11.019.

[37] O. Coussy, P. Dangla, T. Lassabatère, V. Baroghel-Bouny, The equivalent pore pressure and the swelling and shrinkage of cement-based materials, Materials and Structures 37 (2004) 15-20. doi:10.1617/14080

[38] E. M. Gartner, J. F. Young, D. A. Damidot, I. Jawed, Hydration of portland cement, in: Structure and performance of cements, no. 2, 2001, pp. 57-108.

[39] F. Rajabipour, G. Sant, J. Weiss, Interactions between shrinkage reducing admixtures ( SRA ) and cement paste's pore solution, Cement and Concrete Research 38 (2008) 606-615. doi:10.1016/j.cemconres.2007.12.005

${ }_{780}$ [40] I. Maruyama, J. Rymeš, M. Vandamme, B. Coasne, Cavitation of water in hardened cement paste under short-term desorption measurements, Materials and Structures 51 (6) (2018) 159. doi:10.1617/s11527-018-1285-x.

[41] M. B. Pinson, T. Zhou, H. M. Jennings, M. Z. Bazant, Inferring pore connectivity from sorption hysteresis in multiscale porous media, Journal 
of Colloid and Interface Science 532 (July 2015) (2018) 118-127. doi: $10.1016 / j \cdot j$ cis.2018.07.095.

[42] M. Thommes, B. Smarsly, M. Groenewolt, P. I. Ravikovitch, A. V. Neimark, Adsorption hysteresis of nitrogen and argon in pore networks and characterization of novel micro- and mesoporous silicas, Langmuir 22 (2) (2006) 756-764. doi:10.1021/la051686h.

[43] S. Brunauer, P. H. Emmett, E. Teller, Adsorption of gases in multimolecular layers, Journal of the American Chemical Society 60 (1) (1938) 309-319.

[44] R. S. Mikhail, S. Selim, Adsorption of organic vapors in relation to the pore structure of hardened Portland cement pastes, Highway Research Board Special Report (1966) 123-134.

[45] V. Baroghel-Bouny, J. Godin, Experimental study on drying shrinkage of ordinary and high-performance cementitious materials, in: International RILEM Workshop on Shrinkage of Concrete (Shrinkage 2000), Paris, 2000, pp. $215-232$.

[46] S. H. Doerr, R. A. Shakesby, R. P. Walsh, Soil water repellency: Its causes, characteristics and hydro-geomorphological significance, Earth Science Reviews 51 (1-4) (2000) 33-65. doi:10.1016/S0012-8252(00)00011-8

[47] R. Deshpande, D.-W. Hua, D. M. Smith, C. J. Brinker, Pore structure evolution in silica gel during aging/drying. III. Effects of surface tension, Journal of Non-Crystalline Solids 144 (1992) 32-44. doi:10.1016/ S0022-3093(05) 80380-1.

[48] S. S. Prakash, C. J. Sankaran, A. J. Hurd, S. M. Rao, Silica aerogel films prepared at ambient pressure by using surface derivatization to induce reversible drying shrinkage, Nature 374 (6521) (1995) 439-443. doi:10.1038/374439a0. 
[49] X. Zhou, L. Zhong, Y. Xu, Surface modification of silica aerogels with trimethylchlorosilane in the ambient pressure drying, Inorganic Materials 44 (9) (2008) 976-979. doi:10.1134/S0020168508090148.

[50] P. B. Sarawade, J. K. Kim, A. Hilonga, H. T. Kim, Preparation of hydrophobic mesoporous silica powder with a high specific surface area by surface modification of a wet-gel slurry and spray-drying, Powder Technology 197 (3) (2010) 288-294. doi:10.1016/j.powtec.2009.10.006.

[51] N. Shokri, P. Lehmann, D. Or, Effects of hydrophobic layers on evaporation 1 from porous media, Geophysical Research Letters 35 (19) (2008) 1-4. doi: 820 10.1029/2008GL035230. 